\title{
La categoría campesino y sus representaciones en Colombia: polisemia histórica y regional
}

The peasant category and its representations in Colombia: historical and regional polysemy

Vladimir Montaña Mestizo*

Natalia Robledo Escobar*

Soraya Maite Yie Garzón ${ }^{* * *}$

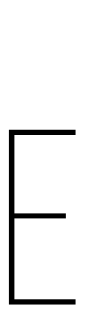

n noviembre de 2018, la Asamblea General de las Naciones Unidas (ONU) emitió la Declaración sobre los Derechos de los Campesinos y Otras Personas que Trabajan en las Zonas Rurales. Su aprobación ocurrió luego de dieciséis años de una intensa campaña liderada por La Vía Campesina (LVC), en favor de la creación de un instrumento jurídico internacional que protegiera los derechos de los campesinos y campesinas. La idea nació de organizaciones agrarias de Indonesia, cuyos dirigentes la plantearon durante los encuentros de LVC (Edelman 2017, 86-87). Con ello, lograron que este movimiento agrario transnacional promocionara la declaración ante la ONU.

Por la misma época de la declaración de la ONU, una sentencia de la Corte Constitucional, con ponencia de la magistrada Patricia Salazar (2018), les ordenó al Ministerio del Interior, al Departamento Administrativo Nacional de Estadística (DANE), a la Presidencia de la República, al Ministerio de Agricultura y Desarrollo Rural, y al Instituto Colombiano de Antropología e Historia (ICANH) la realización de:

\footnotetext{
* $\quad$ vladimir.montana.mestizo@gmail.com / https://orcid.org/0000-0001-8521-9471

** natalia.robledo@uexternado.edu.co / https://orcid.org/0000-0002-9462-4441

***_maiteyie@yahoo.com / https://orcid.org/0000-0002-7305-0901
} 
estudios complementarios al Censo Agropecuario 2014 y al Censo Poblacional 2018 que permitan delimitar a profundidad el concepto "campesino”, contabilizar a los ciudadanos que integran ese grupo poblacional y además que, en cabeza del Grupo de Asuntos Campesinos del Ministerio del Interior, se identifique la situación actual de la población campesina y se apoye la formulación y seguimiento de planes, programas y políticas públicas que permitan la materialización del derecho fundamental a la igualdad material que le asiste al campesinado colombiano.

Como resultado de dicha sentencia, se conformó una comisión de expertos cuya labor fue elaborar un concepto de campesino que condujera a su uso como categoría censal ${ }^{1}$. La comisión partía de que, sin saber quiénes ni cuántos eran los campesinos y campesinas, era imposible promulgar políticas públicas efectivas que restauraran el vacío de ciudadanía que han padecido históricamente.

La sentencia de la Corte Constitucional fue precedida por una tutela interpuesta en 2017 (fallo de tutela STP2028-2018²) por “1700 campesinas y campesinos”, con el apoyo de Dejusticia, que llevaba por título Para que el campesinado cuente tiene que ser contado. La tutela se inscribe en un movimiento más amplio en favor del reconocimiento del campesinado como sujeto político y de derechos del que hacen parte varias organizaciones campesinas del país. Dicho movimiento ha contado con mayor acogida en las regiones de Nariño, Cauca, Tolima, Huila, Putumayo, Catatumbo, Cesar, sur de Bolívar y parte de los Llanos Orientales, lugares en donde predominan uno o varios de los siguientes factores: hay presencia de distintos grupos sociales rurales, algunos de los cuales reivindican una identidad étnica; se presentan conflictos en torno al ordenamiento y uso del suelo; hay presencia de cultivos de uso ilícito; tienen influencia organizaciones sociales, movimientos y partidos políticos que apoyan el otorgamiento de derechos diferenciales a la población que se identifica como campesina.

Un antecedente de dicho movimiento lo constituye el Mandato Agrario, que resultó del encuentro de varias organizaciones sociales de base rural y agraria del país en 2003. Argumentando la existencia de una deuda histórica por

1 La comisión estuvo conformada por investigadores sobre el campesinado y la ruralidad colombiana, conocedores de las dinámicas de las organizaciones sociales y de la política pública del país, quienes fueron convocados por la Procuraduría Delegada para Asuntos Agropecuarios y manifestaron explícitamente su disponibilidad ad honorem para el cumplimiento de la tarea encomendada. Los comisionados fueron: Juan Guillermo Ferro Medina, Carlos Arturo Duarte Torres, Absalón Machado Cartagena, Darío Fajardo Montaña, Olga Lucía Acosta Navarro, Ángela María Penagos Concha, Francisco Gutiérrez Sanín y Marta María Saade Granados, quien además fungió como secretaria técnica de la comisión por parte del ICANH (Saade 2020, 14).

2 Este fallo puede consultarse en https://www.dejusticia.org/wp-content/uploads/2018/02/FalloCorte-Suprema-Tutela-Campesinado.pdf 
parte de la sociedad y en especial del Estado, en dicho documento se introdujo la búsqueda del "Reconocimiento político del campesinado como sujeto de derechos específicos” (Plataforma Colombiana de Derechos Humanos, Democracia y Desarrollo 2004). Como varios autores han planteado, desde el último tercio del siglo pasado, la gramática del reconocimiento les dio forma a las luchas sociales de quienes, en distintas partes del globo, se identifican con categorías que tienen por eje la raza, la etnicidad, el género o la sexualidad (Fraser 1997; Honnet y Fraser 2003; Taylor 1993). Colombia no ha sido la excepción. Esto ocurrió, primero, entre grupos que reivindican una condición étnica, y luego, poco a poco, entre otros sectores del país.

Como lo muestra María Clemencia Ramírez en este volumen de la $R C A$, tal fue el caso de los campesinos cocaleros que se movilizaron en la segunda mitad de la década de los noventa contra la política de fumigación de cultivos ilícitos. Con la redacción del Mandato Agrario, unos años después, se hizo aún más evidente que la gramática del reconocimiento venía acentuándose en una parte de los dirigentes campesinos y sus asesores, algunos de quienes tenían experiencia de trabajo con organizaciones étnicas. Fue así como algunos movimientos agrarios y campesinos sumaron demandas por el reconocimiento a las tradicionales demandas redistributivas - como las luchas por el acceso a la propiedad de la tierra y por una mayor inversión del Estado en las zonas rurales-. Estas reivindicaciones partieron de la idea de que las fallas redistributivas estaban profundamente ligadas a la invisibilización o al desprecio frente a los aportes de los sujetos y territorios rurales a la construcción y el desarrollo de la nación.

No obstante, no fue sino hasta la década pasada cuando el movimiento en favor del reconocimiento del campesinado como sujeto colectivo de derechos se consolidó en nuestro país. Dicho movimiento se expresó en demandas específicas dirigidas al Estado en distintos espacios de interlocución y mediante el uso de diversos canales. Algunos de esos espacios hicieron parte de los mecanismos de participación de la sociedad civil en las negociaciones de la década pasada entre el Gobierno y las guerrillas. En otros casos, resultaron de los acuerdos entre el Gobierno nacional y los gobiernos departamentales con organizaciones agrarias, campesinas y étnicas que se movilizaron, entre otros, en los paros nacionales agrarios de 2013, 2014 y 2016. Adicionalmente, algunas organizaciones agrarias y campesinas del país, actuando en nombre propio o como parte de plataformas más amplias y apoyándose en una red de expertos localizados en la academia y en instituciones del Estado, han desarrollado un ejercicio de movilización del derecho para lograr la inclusión de los términos campesino y campesina como categorías censales. Este es, por ejemplo, el caso del proyecto legislativo impulsado por el senador Alberto Castilla, del Polo Democrático Alternativo (PDA), de la 
tutela ya mencionada, y del reciente proyecto de referendo por el reconocimiento campesino, promovido por la Asociación Nacional de Usuarios Campesinos (ANUC).

En la década en que se implementaron todas esas acciones, algunas de las más influyentes organizaciones campesinas - la Federación Nacional Sindical Unitaria Agropecuaria (Fensuagro), la Asociación Nacional de Usuarios Campesinos - Unidad y Reconstrucción (ANUC-UR) y el Coordinador Nacional Agrario (CNA) - habían establecido fuertes vínculos con la Coordinadora Latinoamericana de Organizaciones Campesinas (CLOC) y con LVC (Cepeda y Muñoz 2020). Como parte de esos vínculos, sus dirigentes habían participado en los encuentros de ambas plataformas, en los que se debatían los contenidos del proyecto de declaratoria y las medidas para impulsar el apoyo de los Gobiernos a su trámite ante la ONU.

Con todo, la lucha por el reconocimiento del campesinado como sujeto colectivo de derechos en el país también tiene su base en varios procesos particulares del contexto colombiano. En primer lugar, a casi dos décadas de promulgada la Constitución de 1991, se hicieron notorias las ventajas y limitaciones de la política de reconocimiento de derechos diferenciales a grupos étnicos en la búsqueda por lograr mejores condiciones de acceso a bienes materiales, espacios de decisión política y estima social. Aunque dicha política resultó insuficiente para garantizar los derechos de las poblaciones con membresía étnica, parecía ofrecer nuevos instrumentos legales para luchar por su cumplimiento. En el lenguaje jurídico, la diferencia cultural se convirtió en una base importante para el reclamo de derechos políticos, sociales, culturales y ambientales. Aunque inicialmente los grupos étnicos fueron asumidos como portadores naturales de esa diferencia, con el tiempo se abrió el camino para que otros actores buscaran convertirse en nuevos sujetos colectivos de derechos.

En segundo lugar, en diferentes áreas rurales del país se expresaron - a veces de forma violenta - tensiones sociales entre individuos, poblaciones y organizaciones incluidas dentro de las categorías étnicas, por un lado, y aquellos que no lo estaban, por el otro. Estos conflictos se dieron en el marco de disputas por la tierra, el acceso a derechos sociales, la presencia de cultivos ilícitos, la relación con actores armados, el acceso a recursos estatales, la política ambiental y diferencias ideológicas que se expresaron en la cercanía o membresía a organizaciones sociales y partidos políticos diversos, entre muchos otros problemas y cuestiones del mundo rural. En algunos casos, estas tensiones fueron propiciadas o incluso atizadas por los cambios en las condiciones de interacción entre unos y otros, derivados a su vez de la política de reconocimiento étnico enmarcada 
en el multiculturalismo (Bocarejo 2015; Duarte 2019; Rincón 2009; Ruiz Serna 2006; Vélez 2018). La existencia de un tratamiento estatal desigual hacia individuos, poblaciones y organizaciones rurales tendió a profundizar, por el juego de contraste, un sentimiento de desconocimiento entre quienes se identifican como campesinos de su condición de sujetos políticos y de derechos.

En tercer lugar, desde la década de los noventa, pequeños y medianos productores fueron duramente afectados por la implementación del modelo neoliberal en el país. Las políticas de privatización y apertura económica condujeron a un menor respaldo del Estado a la producción, así como a un aumento progresivo de las importaciones de alimentos y, en consecuencia, a la pérdida de acceso a una parte considerable del mercado interno. A la crisis económica de muchas familias campesinas se le sumaron los efectos de un modelo de desarrollo rural basado en el agronegocio y la extracción de minerales e hidrocarburos. De este modo, a problemas de vieja data, como la distribución inequitativa de la tierra, las precarias condiciones de trabajo en el campo, la baja inversión estatal, la asistencia técnica insuficiente y las difíciles condiciones de acceso a mercados, se añadió la ausencia de mecanismos efectivos de control sobre los usos del suelo, la conservación del medio ambiente y el acceso al agua. Esta situación contribuyó a que la idea de demandar el reconocimiento del campesinado como colectivo de derechos cobrara fuerza en algunas regiones, especialmente en aquellas donde se trazaron grandes proyectos minero-energéticos, como ocurre en varias zonas de Nariño, Tolima, Cauca y el Catatumbo.

En cuarto lugar, a inicios de esa misma década se hicieron públicas las negociaciones entre el Gobierno colombiano y las guerrillas de las Fuerzas Armadas Revolucionarias de Colombia - Ejército del Pueblo (FARC-EP) y el Ejército de Liberación Nacional (ELN). Con ello, algunas organizaciones campesinas participaron en debates en torno a la paz y el desarrollo rural. Dicha situación favoreció la inscripción de algunas de sus demandas en los pliegos de negociación, principalmente en el caso de las negociaciones con la primera de esas guerrillas. Asimismo, se gestaron nuevas condiciones para la movilización social, lo que contribuyó a que las organizaciones campesinas ganaran relevancia como sujetos políticos.

\section{II}

Con este dosier queremos aportar a los estudios campesinos y al debate antropológico sobre las políticas de la diferencia y la identidad mediante la presentación 
de trabajos que, más que ofrecer una definición de campesino ${ }^{3}$, se preguntan por los modos en los que ha operado y está operando la categoría en escenarios, relaciones y procesos históricos concretos. Nos interesó particularmente reunir investigaciones que dieran cuenta de: 1) el carácter espacial e históricamente situado de las categorías y representaciones sociales; 2) sus variaciones, dependiendo de la posición de sujeto, desde las cuales ocurren las prácticas de categorización y representación; 3) su participación en los conflictos y luchas sociales; y 4) la interacción entre categorías y de estas con representaciones sociales ligadas a los sujetos rurales. Como explicamos a continuación, tales cuestiones resultan de la atención a cuatro hechos ampliamente reconocidos, pero que suelen ser obviados en muchos análisis sobre la categoría campesino y las representaciones asociadas a esta.

1. Trabajos como los de Gros (1991), Tocancipá (1998, 2005), Salgado (2002), González (2019) y Alonso (2020), para Colombia; Báez (2010) y Bartra (2010), para México; Almeida (2007), Marques (2008), Wanderley (2014) y Lombardi y Schiavinatto (2017), para Brasil; Lombardi y Schiavinatto (2017), para Uruguay, Argentina y Paraguay; y Lagos (1997), para Bolivia, han mostrado importantes variaciones espaciales y temporales en los usos de la categoría campesino y de sus traducciones a otras lenguas en América Latina. Tales variaciones también están presentes en las distintas regiones colombianas. Esto nos motivó a preguntarnos por la manera en la que los regímenes dominantes de categorización y representación intervienen en los procesos de configuración regional y, por ende, en la administración y producción de espacios, poblaciones y naturalezas ligados con diversos mecanismos de acumulación del capital.

Creemos, a su vez, que esas variaciones se anclan en procesos históricos, por lo cual le apostamos a nutrir la mirada de las prácticas de categorización y representación contemporáneas con la indagación de sus continuidades y transformaciones en el tiempo. Esta apuesta, que nos ubica cerca de una fenomenología de la vida simbólica, a cuyo desarrollo exhortó Marshal Sahlins (1997) fundándose en una crítica a las distinciones sociales occidentales como marco interpretativo de la antropología, se orienta a observar las categorías de ordenamiento social que contribuyen tanto a la estabilidad como al cambio sociocultural. En palabras de Sahlins, "toda reproducción de la cultura es una alteración, en tanto de organizaciones campesinas o las instituciones del Estado. Tal es el caso de los documentos editados por el ICANH (Saade 2018) y por Bautista et al. (2020), y de los comentarios de Rincón, Benavídez, y Duarte y Montenegro incluidos en la versión comentada del concepto de campesino proferido por la Comisión de Expertos (Saade 2020). 
que en la acción de las categorías por las cuales se orquesta un mundo presente recogen cierto contenido empírico nuevo” $(1997,135)$.

2. Como lo describe Marc Edelman en este dosier, en eventos académicos, organizativos e institucionales ligados al movimiento en favor del reconocimiento del campesinado como sujeto de derechos, se han puesto en juego formas divergentes de categorizar y representar a los habitantes rurales y a quienes se dedican al trabajo agropecuario. Tal hecho nos recuerda que las prácticas de categorización y representación se llevan a cabo desde posiciones de sujeto específicas (Hall 1997). En términos analíticos, esto implica atender a los modos divergentes en los que la categoría campesino y otras semejantes se activan por sujetos que hablan desde posiciones específicas, que tienen como eje la clase, el género, la raza y la etnicidad, pero también por el campesinado mismo y quienes asumen la posición del Estado, la academia, las iglesias, los gremios, los partidos políticos y las organizaciones sociales.

3. Otro hecho que ha salido a flote en los eventos mencionados es la existencia de profundos desacuerdos sobre los modos de denominar a los sujetos del mundo rural y especialmente a quienes se dedican al trabajo agropecuario. El movimiento en favor de la aprobación de la declaratoria de la ONU incluyó discusiones en el interior de LVC sobre el término adecuado para nombrar al sujeto de ella. Algo semejante ha ocurrido en Colombia. En el marco del movimiento en favor del reconocimiento constitucional del campesinado como sujeto de derechos, diferentes actores (dirigentes sociales, funcionarios públicos, juristas, defensores de derechos humanos y académicos) han debatido acerca de cómo nombrar en las normas, instituciones e instrumentos de legibilidad estatal a quienes habitan y trabajan en el campo colombiano. Los debates mencionados en torno al uso de la categoría campesino nos recuerdan que las prácticas de categorización social se inscriben en conflictos sociales (Bourdieu 1984, 2014; Brubaker 2004; Comaroff y Comaroff 2006). Por ello planteamos que cualquier aproximación analítica a las categorías debe considerar los proyectos en tensión que son agenciados a través de ellas y el hecho de que estas arrastran consigo las memorias de los conflictos en los que han estado inscritas. Esto aplica, claro está, a la categoría campesino.

Cabe recordar, además, que lo que está en juego no es únicamente la forma en que un sector de la población nacional es categorizado, sino también las representaciones asociadas a las categorías que se le asignan. Y es que las luchas por el reconocimiento son también luchas en el ámbito de la representación. Al respecto, Hall (1997) plantea que las prácticas de representación participan en los procesos de dominación, así como pueden, por la vía de la resignificación, hacer parte de luchas por la emancipación. 
Al lado de las categorías, las representaciones sociales -como aquellas asociadas a quienes son categorizados como campesinos - tienen efectos en el plano de la regulación y la redistribución, por lo que participan en la configuración y contestación de órdenes sociales caracterizados por la desigualdad. De acuerdo con Bourdieu (1979), en la distinción están las claves del ordenamiento social. Por una parte, las representaciones desempeñan un rol fundamental en la jerarquización de los grupos, en la definición de los comportamientos que se consideran socialmente aceptables en cada caso y en la evaluación de su nivel de cumplimiento con la sociedad más amplia. Por otra parte, las representaciones les dan sustento a las clasificaciones que están en la base de la distribución desigual de la estima social, los bienes y el poder de decisión, pero también de la exposición a distintas formas de explotación, despojo y violencia.

Así, por ejemplo, la representación de los campesinos como sujetos ociosos, o al menos como sujetos trabajadores pero ineficientes, en un contexto en el que este grupo social ha sido predominantemente definido como productor de materias primas y alimentos, ha incidido directamente en el escaso reconocimiento de sus aportes a la construcción y al desarrollo de la nación. De esta manera, ha servido de base para asumir, de manera explícita o de facto, que los recursos públicos deben dirigirse a otros grupos sociales. Así mismo, la representación de los cultivadores de coca como criminales ha legitimado su exclusión de los espacios de decisión en torno a las políticas antinarcóticos y el uso de la represión estatal en su contra (Ramírez 2006). Comprender cómo han sido representados los campesinos en distintos contextos geográficos e históricos ayuda, entonces, a entender las fallas de reconocimiento de quienes se autoidentifican como campesinos, así como las fallas redistributivas que han perpetuado la precariedad y su exclusión de las diferentes instancias de toma de decisiones en los ámbitos local, regional y nacional. Además, ayuda a entender los cambiantes procesos de autoadscripción identitaria a una u otra categoría social.

4. Finalmente, queremos llamar la atención sobre las complejas interacciones que existen entre la categoría campesino y otras categorías sociales disponibles, como las de vecino, aldeano, labrador, libre y, más recientemente, las de colono, trabajador agrícola, pobre rural, pequeño productor, productor, agricultor y emprendedor rural, así como las de mestizo, indígena, indio, negro y afrodescendiente. En efecto, unas y otras han sido leídas desde la diferencia o la similitud, y se han reforzado o sucedido en el tiempo en función de factores como la escala y el tipo de trabajo rural, los usos del suelo, el oficio, la raza, la etnia y, por supuesto, la lectura que hacen de estas categorías las élites y los representantes el Estado. Un ejemplo claro de ello es la campesinización, a inicios del siglo $\mathrm{XX}$, de una parte de los sujetos indígenas (por ejemplo, en los departamentos de 
Nariño y Cauca) y la posterior reetnización de algunos de ellos, así como de sujetos campesinos, ocurrida tras la aprobación de la Constitución de 1991 (Chaves 1998).

Al reconocer la coexistencia de diversas categorías para designar y representar a los pobladores rurales, creemos que es importante avanzar en la comprensión de la manera como interactúan los distintos sistemas de clasificación social. Una primera entrada analítica a esas interacciones recoge la propuesta del enfoque interseccional que está atento a los efectos de la asignación simultánea de categorías ligadas a diferentes estructuras de dominación que se ejercen sobre - y a la vez producen a- los sujetos, especialmente sobre aquellos que ocupan posiciones subordinadas en la sociedad. Aún no se han estudiado de manera suficiente los efectos que tiene sobre individuos y poblaciones concretas el hecho de ser incluidos simultáneamente dentro de la categoría campesino y dentro de rótulos enmarcados en las nociones de clase, raza, etnicidad, género y edad. Con excepción de unos pocos textos (García 2017; Herrera 2016; Hoffman 2016; Sañudo 2015), una mirada interseccional a las identidades campesinas sigue estando pendiente.

Una segunda entrada analítica a las interacciones entre categorías surge al prestar atención a los efectos que tiene la superposición de regímenes clasificatorios en el contenido de categorías como campesino. En este enfoque resulta emblemático el trabajo de Marisol de la Cadena (2007) sobre el mestizo en el contexto peruano, en el cual concluye que se trata de una categoría conceptualmente híbrida, en tanto su contenido resulta ser el efecto de la mezcla de dos sistemas de clasificación: uno basado en la noción colonial de calidad y otro en la noción decimonónica de raza. Consideramos que un análisis semejante puede proponerse para la categoría campesino, cuyo contenido resulta del cruce cambiante, en el tiempo y en el espacio, de sistemas de clasificación que tienen como ejes el lugar de habitación, la propiedad o no sobre la tierra y su tamaño, la escala productiva, el modo de producción, el oficio, la clase, la raza, la etnicidad, la nacionalidad y la relación con el medio ambiente, entre otros.

\section{III}

Este dosier apela a la antropología histórica como aproximación analítica a las políticas y las prácticas identitarias contemporáneas de los pobladores rurales. Partimos de la idea de que conviene mirar el pasado desde una óptica antropológica especialmente atenta a la manera en que las categorías y las represen- 
taciones fueron activadas por diferentes actores, en el marco de interacciones cotidianas y procesos históricos de distinta duración. Igualmente, consideramos que es importante adoptar una mirada sensible a cómo se producía la diferencia en el pasado y a sus efectos multidimensionales.

Esta óptica implica, por una parte, evitar caer en anacronismos que apliquen al pasado las categorías del presente. Se trata de una problemática que fue especialmente trabajada por Gerard Beaur (1999) en su texto "Les catégories sociales à la campagne: repenser un instrument d'analyse”, a propósito de la discusión - formulada por algunos microhistoriadores - sobre la pertinencia de utilizar las categorías sociológicas del presente para analizar a los actores sociales rurales del pasado. Así, por ejemplo, en Colombia sería inconveniente aplicar la categoría de agricultor familiar — que viene siendo impulsada por la Red Nacional de Agricultura Familiar (Renaf) en los últimos años- a los labradores del siglo XIX. Por otra parte, también resulta necesario entender que los usos pasados de una categoría modulan, sin llegar a determinar, sus usos contemporáneos. Es el caso del uso decimonónico de la categoría campesino como un sujeto dedicado casi exclusivamente a la producción agropecuaria. Esta representación se mantiene presente en múltiples escenarios académicos, gubernamentales y organizativos, a pesar de que buena parte de esta población ha venido diversificando sus actividades económicas mediante la pluriactividad y los ingresos extraprediales, en parte por la baja retribución al trabajo agropecuario.

La categoría campesino no es la única a través de la cual ha sido designada la población rural. Así como el universo social cobijado por ciertas categorías es cambiante, las personas también transitan entre ellas. Quien fue reconocido como campesino en un momento dado puede pasar a serlo de otro modo y viceversa. Tanto en Bolivia (Rivera Cusicanqui 2008) como en México (Báez 2010), poblaciones que se hicieron legibles ante el Estado como indígenas hasta las décadas de los sesenta y setenta pasaron a serlo como campesinos para retornar a organizarse bajo la primera categoría en un ejercicio de lucha por el acceso y la conservación de sus tierras. Como sabemos, algo semejante se ha dado en varias regiones de Colombia en torno a procesos de reindigenización (Chaves 1998; Chaves y Zambrano 2009). En Brasil, a partir de la década de los noventa, poblaciones rotuladas como camponesas se han hecho legibles a través de nuevas categorías que funcionan como descriptores de sus condiciones de vida o sus modos de producción, como las de pequenho productor y agricultor familiar (Marques 2008; Wanderley 2014), o como populações tradicionais, indígenas u otras semejantes (Almeida 2007; Lombardi y Schiavinatto 2017).

En el caso europeo, Beckett (1984) muestra cómo la voz peasant es de uso relativamente nuevo en Inglaterra. Hasta hace apenas unos siglos, la voz usual 
para referir al propietario rural era yeoman, que se aplicaba a un grupo rural y agrícola por debajo de la nobleza y, en algunas regiones, por encima del agricultor o husbandman. Estas palabras, por su parte, no representaban a las personas que eran distinguidas como freeholders, farmers o labourers. Beckett explica que, en el contexto inglés, a diferencia de lo que ocurría en la Europa continental, no es tan clara la equivalencia entre ocupante, propietario y cultivador, por tratarse de un contexto fundado en el carácter nobiliario de la propiedad. Si se le asigna a la categoría campesino un significado similar al que ha tenido en países como Francia y la región latinoamericana, podría terminar concluyéndose su desaparición en la Inglaterra de la Baja Edad Media (Beckett 1984). No obstante, en el continente europeo el significado de campesino también se modificó. Esta categoría, que durante el Antiguo Régimen fue asociada con lo bárbaro y lo brutal, cambió progresivamente de significado. Tal como lo mostró tempranamente Barral (1966), el estatus social del campesino frente a la nación francesa cambió en el siglo XIX con el influjo romántico, el advenimiento de la geografía como ciencia del territorio y la retórica paternalista de los movimientos de acción republicana, las corporaciones de agricultores y los movimientos de acción católica rural.

\section{IV}

Pensar y analizar la categoría campesino en su diversidad histórica y regional fue la pauta tanto de la convocatoria como de la selección de textos para la presente edición de la $R C A$. Sin embargo, el resultado no fue el esperado. Si bien recibimos una considerable cantidad de documentos que trabajaban sobre temas rurales y poblaciones a las que los autores y autoras se referían como campesinos, nos sorprendió ver que pocas veces se privilegió, como objeto directo de análisis, la categoría misma o sus usos y representaciones. Varios de los artículos enviados a la convocatoria se planteaban como objetivo definir la categoría de campesino más que abordar, desde una perspectiva histórica o etnográfica, su diversidad de usos y representaciones en contextos particulares. Otro conjunto de trabajos estuvo compuesto por etnografías sobre las prácticas y modos de vida de comunidades campesinas específicas. En ambos casos nos encontramos con trabajos valiosos, que aportaban a la comprensión de las problemáticas rurales y sus retos analíticos, pero que se salían del marco de la convocatoria.

Entre los artículos incluidos en el dosier se encuentra “Genealogía histórica de la categoría de colono: imágenes y representaciones en las zonas de frontera 
y su devenir en campesino colono y campesino cocalero”, en el que María Clemencia Ramírez analiza los usos dados a la categoría colono por parte del Gobierno y los académicos, así como las imágenes asociadas a esta, especialmente en el contexto de la Amazonia occidental donde la colonización constituyó una solución alterna a la reforma agraria del interior. Luego de trazar una genealogía histórica de los procesos de colonización, la autora argumenta que la categoría colono tiene un carácter excluyente para los sujetos a los que se les adscribe, pues invisibiliza su condición de campesinos. Esto sucede especialmente cuando se trata de cultivadores de coca y, aún más, cuando estos pasan de ser nombrados colonos a ser categorizados como colonos cocaleros.

En "La transformación de las representaciones sociales coloniales ante la emergencia de la diferenciación campo-ciudad”, Vladimir Montaña Mestizo presenta el contexto colonial y las categorías usadas para hacer referencia a las poblaciones rurales que no eran definidas como indígenas, es decir, a los mestizos, libres de todos los colores y vecinos. El documento plantea que, a partir de la segunda mitad del siglo XVIII, las pautas de residencia en el altiplano cundiboyacense comenzaron a ser el factor determinante en la distinción social. El residir en el campo (o en la ciudad), en un conglomerado, en una pequeña aldea o en lo despoblado no había sido hasta entonces un factor determinante en la distinción del otro. Hasta este periodo se era español, indio, vecino o libre, con independencia de las pautas y del lugar de residencia. En esta medida, el trabajo constituye un aporte para quienes estén interesados en la comprensión de las relaciones entre procesos históricos de ordenamiento del espacio y formas de categorización y representación de los habitantes rurales en nuestro país.

El artículo de Natalia Robledo Escobar y Carl Henrik Langebaek Rueda, "Lo que va del labrador al campesino: representaciones sociales en el actual territorio colombiano, 1780-1866”, analiza la manera como fueron representados los agricultores en el contexto mencionado. Los autores centran la mirada en textos producidos por funcionarios peninsulares, élites letradas y autores costumbristas, y argumentan que el paso de labrador a campesino como término de uso predominante refleja la ruptura que propició la independencia en la representación social de los agricultores. Con ello, la representación de los campesinos, si bien se basó en la asignación de atributos similares a los que se les asignaron a los labradores, fue más benigna y estuvo ligada al deseo de incrementar la productividad agropecuaria y de fortalecer la articulación de Colombia con los mercados internacionales. Esta mirada les atribuyó un papel más positivo en el futuro del país, los hizo funcionales a la construcción de la nueva nación y permitió que se dieran pasos tendientes a considerarlos un elemento importante de la identidad nacional. 
El artículo de Soraya Maite Yie Garzón, “Aparecer, desaparecer y reaparecer ante el Estado como campesinos”, rastrea los usos históricos del término campesino en los últimos cien años en Colombia, tanto en políticas dirigidas a la población rural como en procesos de movilización rural y agraria. Desde allí, busca aportar a la comprensión del movimiento social actual en favor del uso de esta categoría en las normas, políticas e instrumentos de medición estatal. Yie argumenta que al menos dos roles históricos asumidos por esta categoría permiten comprender su resonancia actual: mediar entre el Estado y amplios sectores de la población rural, y participar en la unificación y la diferenciación de esta última. El trabajo muestra, entonces, la pluralidad de sentidos que arrastra la categoría campesino en Colombia, dado su papel en el devenir del país y su potencial para evocar las memorias de lucha heterogéneas de la población rural.

Finalmente, el dosier cierra con “¿Qué es un campesino? ¿Qué son los campesinados? Un breve documento sobre cuestiones de definición”, traducción de una conferencia presentada por Marc Edelman en una reunión del grupo de trabajo intergubernamental que asesoró la Declaración sobre los Derechos de los Campesinos y de Otras Personas que Trabajan en las Zonas Rurales. Allí, el autor ofrece un panorama de las variaciones históricas y regionales en los significados de la categoría campesino (o sus traducciones a otras lenguas). También brinda un balance de las maneras en que ha sido definido el campesino desde la academia, las regulaciones y los movimientos agrarios transnacionales ligados con el movimiento en favor de la declaratoria. A partir de allí, su trabajo muestra cómo las formas de categorización y conceptualización de los sujetos rurales median tanto su relación con los Estados y las agencias transnacionales de gobierno como las dinámicas globales de articulación y movilización social de la población rural. En particular, analiza el caso de LVC y cómo desde el movimiento social liderado por ella en favor de la declaratoria se ha movilizado una definición que implica críticas profundas al statu quo y a la estructura rural y agraria. Por último, Edelman muestra cómo existen definiciones normativas que van distinguiendo progresivamente nuevas categorías y subcategorías de diferenciación dentro del campesinado y reconocen que este grupo también es heterogéneo.

Deseamos que los manuscritos aquí reunidos contribuyan a ampliar nuestro conocimiento de las formas histórica, espacial y socialmente situadas de categorización y representación de pobladores rurales del país y la región, de los procesos en que se inscriben y de sus variados efectos. A su vez, esperamos que este dosier convoque a nuevas investigaciones sobre los diversos significados que han sido y son asociados a las palabras campesino y campesina, y que contribuya a construir análisis más complejos de las políticas identitarias contemporáneas de quienes se reivindican como tales. 


\section{Referencias}

Almeida, Mario William Barbosa de. 2007. "Narrativas agrárias e a morte do campesinato". Ruris, Campinas 1 (2): 157-186. https://www.ifch.unicamp.br/ojs/index.php/ruris/article/ view/656

Alonso Acosta, Irene. 2020. "La voz campesina en la esfera pública colombiana en el siglo XX a través de los periódicos de la ANUC y sus antecedentes. Un recorrido por sus representaciones, representantes y representados”. Trabajo de grado, Departamento de Antropología, Pontificia Universidad Javeriana, Bogotá.

Báez Landa, Mariano. 2010. "De indígenas a campesinos. Miradas antropológicas de un quiebre paradigmático”. Ruris 3 (2): 55-74. https://www.ifch.unicamp.br/ojs/index.php/ ruris/article/view/695

Barral, Pierre. 1966. "Note historique sur l'emploi du terme de paysan”. Études Rurales 21: 72-80. https://doi.org/10.3406/rural.1966.1265

Bartra, Armando. 2010. Campesindios. Aproximaciones a los campesinos de un continente colonizado. La Paz: Instituto para el Desarrollo Rural de Sudamérica.

Bautista, Ana Jimena, Diana Isabel Güiza Gómez, Ana María Malagón y Rodrigo Uprimny. 2020. La constitución del campesinado: luchas por el reconocimiento y la redistribución en el campo jurídico. Bogotá: Dejusticia.

Beckett, John Vincent. 1984. “The peasant in England: a case of terminological confusion?”. The Agricultural History Review 32 (2): 113-123. https://www.jstor.org/stable/40274332

Beur, Gérard. 1999. "Les catégories sociales à la campagne: repenser un instrument d'analyse”. Annales de Bretagne et des pays de l'Ouest 106 (1): 159-176. https://doi.org/10. 3406/abpo.1999.4020

Bocarejo, Diana. 2015. Tipologías y topologías indígenas en el multiculturalismo colombiano. Bogotá: Instituto Colombiano de Antropología e Historia; Pontificia Universidad Javeriana; Universidad del Rosario.

Bourdieu, Pierre. 1979. La distinction. Critique sociale du jugement. París: Minuit.

—. 1984. “Espace social et genèse des 'classes””. Actes de la recherche en sciences sociales 52-53: 3-14. https://doi.org/10.3406/arss.1984.3327

-. 2014. Sobre el Estado. Cursos de la College de France. Barcelona: Anagrama.

Brubaker, Rogers. 2004. Ethnicity without groups. Cambridge: Harvard University Press.

Cepeda, Carolina y Julián Muñoz Londoño. 2020. "Las articulaciones globales del campo colombiano: Fensuagro, el Coordinador Nacional Agrario y La Vía Campesina”. Temas Sociológicos 27: 245-273. https://doi.org/10.29344/07196458.27.2472

Chaves, Margarita. 1998. "Identidad y representación entre indígenas y colonos en la Amazonía colombiana”. En Modernidad, identidad y desarrollo: construcción de sociedad y recreación cultural en contextos de modernización, editado por María Lucía Sotomayor, 273-286. Bogotá: ICANH; Ministerio de Cultura; Colciencias. 
Chaves, Margarita y Marta Zambrano. 2009. "Desafíos a la nación multicultural. Una mirada comparativa sobre la reindianización y el mestizaje en Colombia”. En Repensando los movimientos indígenas, editado por Carmen Martínez, 215-249. Quito: Flacso.

Comaroff, John y Jen Comaroff. 1992. Studies in the ethnographic imagination. Boulder: Westview Press.

De la Cadena, Marisol. 2007. “Son los mestizos híbridos?”. En Formaciones de indianidad: articulaciones raciales, mestizaje y nación en América Latina, editado por Marisol de la Cadena, 83-118. Popayán: Envión.

Duarte, Carlos. 2019. Desencuentros territoriales. La emergencia de los conflictos interétnicos en el Cauca. Vol. 1. Bogotá: ICANH.

Edelman, Marc. 2017. Movimientos agrarios transnacionales: historia, organización y políticas de lucha. La Paz: Fundación Tierra.

Fraser, Nancy. 1997. Justicia interrupta: reflexiones críticas desde la posición postsocialista. Bogotá: Siglo del Hombre; Ediciones Uniandes.

García Becerra, Andrea. 2017. "Mujeres campesinas, afrodescendientes e indígenas en Colombia. Prácticas políticas y cotidianas del cuidado”. Pensares y Quehaceres. Revista de Políticas de la Filosofía 4: 131-152.

González, María José. 2019. "Cartas al desarrollo: sujeto campesino e ideal de progreso en Colombia (1950-2019)”. Tesis de maestría, Departamento de Estudios Culturales, Pontificia Universidad Javeriana, Bogotá.

Gros, Christian. 1991. Colombia indígena. Identidad cultural y cambio social. Bogotá: Cerec.

Hall, Stuart, ed. 1997. Representation - cultural representations and signifying practices. Londres; Thousand Oaks; Nueva Delhi: Open University.

Herrera, Arango, Johana. 2016. Sujetos a mapas: etnización y luchas por la tierra en el Caribe colombiano. Bogotá: Pontificia Universidad Javeriana.

Hoffmann, Odile. 2016. "Divergencias construidas, convergencias por construir. Identidad, territorio y gobierno en la ruralidad colombiana”. Revista Colombiana de Antropología 52: 17-39. https://doi.org/10.22380/2539472X1

Honneth, Axel y Nancy Fraser. 2003. ¿Redistribution or recognition? A political-philosophical exchange. Nueva York; Londres: Verso.

Lagos, María L. 1997. Autonomía y poder: dinámica de clase y cultura en Cochabamba. La Paz: Plural Editores.

Lombardi, Thais Tartalha do Nascimento y Monica Schiavinatto. 2017. Questão agrária, direitos e diversidade do campesinato em alguns países da América. Ponencia presentada en el Congres of Latin American Studies Association, Lima, Perú, 29 de mayo al 1. ${ }^{\circ}$ de junio.

Marques, Marta Inês Medeiros. 2008. “A atualidade do uso do conceito de camponês”. Revista Nera 11 (12): 57-67. https://doi.org/10.47946/rnera.v0i12.1399

Plataforma Colombiana de Derechos Humanos, Democracia y Desarrollo. 2004. Políticas agrarias para Colombia 2003. Bogotá: ILSA. 
Ramírez, María Clemencia. 2006. Entre el Estado y la guerrilla: identidad y ciudadanía en el movimiento de los campesinos cocaleros del Putumayo. Bogotá: ICANH.

Rincón García, John Jairo. 2009. "Diversos y comunes: elementos constitutivos del conflicto entre comunidades indígenas, campesinas y afrocolombianas en el departamento del Cauca”. Análisis Político 22 (65): 53-93. https://revistas.unal.edu.co/index.php/anpol/article/view/45959

Rivera Cusicanqui, Silvia. 2008. "El potencial epistemológico y teórico de la historia oral: de la lógica instrumental a la descolonización de la historia”. En Teoria crítica dos dereitos humanos no século XXI, 157-178. Porto Alegre: Edipucrs.

Ruiz Serna, Daniel. 2006. Nuevas formas de ser negro. Consideraciones sobre las identidades entre la gente chilapa y negra del Bajo Atrato. Colección Monografías 37. Caracas: Universidad Central de Venezuela.

Saade, Marta, ed. 2018. Elementos para la conceptualización de lo campesino en Colombia. Documento técnico. Bogotá: ICANH.

-. 2020. Conceptualización del campesinado en Colombia. Documento técnico para su definición, caracterización y medición. Bogotá: ICANH.

Sahlins, Marshall. 1997. Islas de historia. La muerte del capitán Cook. Memoria, antropología e historia. Barcelona: Gedisa.

Salazar Cuellar, Patricia. (Magistrada ponente). 2018. STP2028-2018. Radicación n. 96414. Acta 47.

Salgado, Carlos. 2002. "Los campesinos imaginados”. Cuadernos de Tierra y Justicia, 6. Bogotá: ILSA. http://www.ilsa.org.co/biblioteca/Cuadernos_Tierra_y_Justicia/Cuadernostierrayjusticia_6/Los_campesinos_imaginados.pdf

Sañudo, María Fernanda. 2015. Tierra y género. Bogotá: Pontificia Universidad Javeriana.

Taylor, Charles. 1993. El multiculturalismo y la "política del reconocimiento". Ciudad de México: Fondo de Cultura Económica.

Tocancipá Falla, Jairo. 1998. "Los estudios campesinos en la antropología colombiana 19401960”. Problemas Políticos Latinoamericanos 1 (4-5): 171-202. https://vertov14.files.wordpress.com/2016/08/tocancipa-1940-1960-introduction-2.pdf

-. 2005. "El retorno de lo campesino: una revisión de los esencialismos y la heterogeneidad de la antropología”. Revista Colombiana de Antropología 41: 7-41. https://doi. org/10.22380/2539472X.1201

Vélez-Torres, Irene. 2018. "Una mirada histórica y socio-ambiental para repensar y renombrar los conflictos entre comunidades étnicas del Alto Cauca, Colombia”. El Ágora U.S.B. 18 (1): 38-54. https://doi.org/10.21500/16578031.3058

Wanderley, Maria de Nazareth Baudel. 2014. "O campesinato brasileiro: uma história de resistência”. Revista de Economia e Sociologia Rural 52 (1): 25-44. https://doi.org/10.1590/ S0103-20032014000600002 